\title{
Mandibular Fractures and Associated Factors at a Tertiary Care Hospital
}

\author{
Srikanth Gadicherla,, Prem Sasikumar, ${ }^{1}$ Satpal Singh Gill, ${ }^{1}$ Manish Bhagania,, Abhay Taranath \\ Kamath, ${ }^{1}$ and Kalyana Chakravarthy Pentapati ${ }^{2,}$ \\ ${ }^{1}$ Department of Oral and Maxillofacial Surgery, Manipal College of Dental Sciences, Manipal University, Karnataka, India \\ ${ }^{2}$ Department of Public Health Dentistry, Manipal College of Dental Sciences, Manipal University, Karnataka, India \\ "Corresponding author: Kalyana Chakravarthy Pentapati, Department of Public Health Dentistry, Manipal College of Dental Sciences, Manipal University, Karnataka, India. Tel: \\ +91-9916036303, E-mail: drkalyan81@gmail.com
}

Received 2015 June 09; Revised 2015 December 31; Accepted 2016 September 03.

\begin{abstract}
Objectives: The aim of this study was to evaluate the distribution, etiology and type of mandibular fractures in subjects referred to our institution.

Methods: A retrospective study of 689 subjects, during the period from May 2010 to September 2013 with mandibular fractures was conducted. Information on age, gender, mechanism of injury and sites of trauma was obtained from the trauma registry. Data were tabulated and analyzed statistically.

Results: A total of 653 subjects had mandibular fractures, out of which 574 were males. The mean age of the participants was 31.54 \pm 13.07. The majority of the subjects were between $21-40$ years of age, in both males (61.7\%) and females (54.4\%). The major cause of fractures was road traffic accidents (87.4\%) followed by fall (6.9\%) and assault (4\%), with the least frequent being gunshot injuries (0.3\%). Almost half of the patients had parasymphysis fractures (50.2\%), followed by angle (24.3\%), condyle (20.4\%), ramus (2.3\%) and coronoid (2\%). A total of 115 patients had bilateral fractures out of which 29 had parasymphysis, 12 had body fractures and 74 had bilateral condylar fractures. Double mandibular fractures were reported in 193 subjects; out of which 151 subjects had double contralateral and 42 had double unilateral fractures. Triple unilateral fracture was reported in only one subject. A total of 338 subjects had multiple fractures among the study population.

Conclusions: Mandibular fractures can be complicated and demanding, and have a compelling impact on patients' quality of life. Our study reported that parasymphysis was the most common region involved in mandible fractures.
\end{abstract}

Keywords: Epidemiology, Fractures, Mandible, Trauma

\section{Background}

The first ever inscription on mandibular fractures dates back to $1650 \mathrm{BC}(1)$. Mandibular fractures are twice as common as fractures of the bones of the mid-face and comprise most of injuries treated by an oral and maxillofacial surgeon (2-4). King et al., reported that parasymphyseal fractures were most frequent (35\%), while the least common were dentoalveolar (1.3\%) and ramus fractures (5.7\%) (5). In a retrospective study by de Matos et al., and Elgehani and Orafi, it was reported that condyle, body, symphysis and parasymphysis were the most common mandibular fractures, whereas ramus (4\%) and coronoid (2\%) were the least common fractures $(6,7)$. Galvan reported that body (28\%) followed by the parasymphysis (24\%) were the most common fracture sites while alveolar ridge (3\%) and coronoid (1\%) were the least common areas (8). Other studies on mandibular fractures reported that parasymphysis was the most common fracture $(9,10)$ while coronoid was the least common (10).

Mandibular fractures can involve any of the anatomic sub-sites with simultaneous multiple sites involvement (5). Literature was scant regarding multiple site fractures (double unilateral, contralateral and triple unilateral fractures) in mandible. The patterns and etiology of mandible fractures varied considerably among different study populations. There was an increase in the frequency of fractures due to violent mechanisms along with an increase in incidence of these injuries in adolescents and young adults, especially in urban areas (11-13).

The incidence of mandibular fractures rises as children begin school and peaks during adolescence due to increased unsupervised physical activity and sports. Among all age groups, boys are more commonly affected than girls due to more dangerous physical activities among boys (14, 
15).

Social, cultural and environmental factors vary from one country to another along with varied geographic region, population density, socioeconomic status, regulatory affairs (viz., speed limits, compulsory use of seat belts and helmets) and political era, which influence the incidence and etiology of mandibular trauma.

A clearer understanding of the patterns of mandibular fractures will assist health care providers as they plan the treatment of maxillofacial injuries. Such epidemiological information can also be used to guide the future funding of public health awareness programs targeted for prevention of such injuries.

\section{Objectives}

This study attempted to evaluate the patterns of mandibular fracture retrospectively, based on patient's age, gender and mechanism of injury.

\section{Methods}

A retrospective study was conducted among subjects, who referred with mandibular fractures to the department of oral and maxillofacial surgery, Manipal, from May 2010 to September 2013. A total of 689 subjects, referred to our unit with mandibular fractures during the abovementioned period, were included in the study. The data were obtained from the medical record department by two investigators.

All subjects underwent radiographic assessment to determine the extent of the fracture and its precise pattern as per standard operating procedure. Initially, a list of all the individuals who had oral and maxillofacial $(\mathrm{n}=2508)$ trauma during the study period was obtained from the trauma registry from two resident doctors, who are well versed with the terminologies. They were then screened for mandibular fractures. Next, subject's records were checked for completeness of the data related to gender, age, site of fracture, side and mechanism of injury from their records at the medical records department and immediately entered in predesigned pro forma. Only patients with full information with respect to the above parameters were considered for the study. Exclusion criterion was having incomplete data $(n=36)$. Bilateral fractures are same site fractures on both right and left side of the mandible while double fractures are different fracture sites on same or contralateral side.

\subsection{Statistical Analysis}

All the analysis was done using SPSS version 14 (SPSS Inc, Ill, Chicago, USA). A P-value of $<0.05$ was considered statistically significant. Chi-Square test was done to evaluate the significant differences.

\section{Results}

A total of 653 subjects had mandibular fractures during the study period out of which 574 were males. The mean age of the participants was $31.54 \pm 13.07$. The majority of subjects were in the age range of 21 to 40 , including both males (61.7\%) and females (54.4\%) (Table 1). The major cause for fractures was road traffic accidents (87.4\%) followed by fall (6.9\%) and assault (4\%), with least being gunshot injuries (0.3\%). Almost, half of the patients had parasymphysis fractures (50.2\%), followed by angle (24.3\%) and condyle (20.4\%) with least being ramus (2.3\%) and coronoid (2\%) (Table 2 ).

Table 1. Distribution of Age and Gender Among the Study Population ${ }^{\mathrm{a}}$

\begin{tabular}{lcc}
\hline Age Group & \multicolumn{2}{c}{ Gender } \\
\cline { 2 - 3 } & Male & Female \\
\hline$<20$ & $92(16.0)$ & $22(27.8)$ \\
\hline $\mathbf{2 1}-\mathbf{4 0}$ & $354(61.7)$ & $43(54.4)$ \\
$\mathbf{4 1 - 6 0}$ & $114(19.9)$ & $6(7.6)$ \\
\hline $\mathbf{6 1}-\mathbf{8 0}$ & $14(2.4)$ & $8(10.1)$ \\
\hline
\end{tabular}

${ }^{\mathrm{a}}$ Values are expressed as No. (\%).

A total of 115 patients had bilateral fractures, out of which 29 had parasymphysis, 12 had body fractures and 74 had bilateral condylar fractures. Double fractures were reported in 193, out of which 151 (23.1\%) subjects had double contralateral and 42 (6.4\%) had double unilateral fractures. Triple unilateral fracture was reported in only one subject. A total of 338 subjects had multiple fractures (Table 3).

Among road traffic accident (RTA) subjects, the 21 to 40 year-old age group had significantly higher mandibular fractures than the other age groups $(\mathrm{P}<0.001)$. No significant difference was seen between males and females in the cause of mandibular fracture $(\mathrm{P}=0.458)$ (Table 4$)$.

Prevalence ratios were used to evaluate the relationship between mechanism of injury and site of fracture. It was found that prevalence of coronoid fracture was 4.65 times higher in subjects with assault type of injury. Similarly, symphysis fracture was 3.4 times $(\mathrm{CI}=1.77-6.52, \mathrm{P}<$ 0.001 ) higher in subjects, who had falls, while angle fracture was significantly lower $(\mathrm{OR}=0.285 ; \mathrm{CI}=0.1-0.81 ; \mathrm{P}=$ 0.012). Parasymphysis and body fractures were $1.59(\mathrm{CI}=$ 
Table 2. Distribution of Site and Reasons for Fracture ${ }^{\mathrm{a}}$

\begin{tabular}{|c|c|c|c|c|c|c|}
\hline & Assault & Fall & Gunshot & RTA & Sports & Total \\
\hline Symphysis & 6 & 16 & 0 & 77 & 2 & $101(15.5)$ \\
\hline Parasymphysis & 11 & 19 & 0 & 295 & 3 & $328(50.2)$ \\
\hline Body & 3 & 1 & 2 & 95 & 1 & $102(15.6)$ \\
\hline Angle & 9 & 4 & 2 & 140 & 4 & $159(24.3)$ \\
\hline Ramus & 1 & 0 & 0 & 14 & 0 & $15(2.3)$ \\
\hline Coronoid & 2 & 0 & 0 & 11 & 0 & $13(2.0)$ \\
\hline Condyle & 2 & 9 & 0 & 121 & 1 & $133(20.4)$ \\
\hline Total & 34 & 49 & 4 & 753 & 11 & 851 \\
\hline
\end{tabular}

${ }^{\mathrm{a}}$ Values are expressed as No. (\%).

Table 3. Distribution of Multiple Mandibular Fractures

\begin{tabular}{l|c|c}
\hline \multirow{2}{*}{ Type } & Site & No. (\%) \\
\hline \multirow{2}{*}{ Bilateral } & Parasymphysis & $29(4.4)$ \\
\cline { 2 - 3 } & Body & $12(1.8)$ \\
\cline { 2 - 3 } & Condyle & $74(11.3)$ \\
\hline \multirow{2}{*}{ Double } & Double Contralateral & $151(23.1)$ \\
\cline { 2 - 3 } & Double Unilateral & $42(6.4)$ \\
\hline \multirow{2}{*}{ Triple } & Unilateral & $1(0.2)$ \\
\hline
\end{tabular}

$0.99-2.54 ; \mathrm{P}=0.05)$ and $2.14(\mathrm{CI}=0.96-4.78 ; \mathrm{P}$-value $=0.059)$ times higher among those with RTA while symphysis was significantly lower in RTA $(\mathrm{OR}=0.377 ; \mathrm{CI}=0.22-0.64 ; \mathrm{P}<$ 0.001) (Table 5).

\section{Discussion}

This study evaluated the pattern of mandibular fractures along with the relationship with mechanism of injury and site of fracture. Consequences of facial trauma included feeling embarrassed to smile, laugh and show one's teeth, difficulty in maintaining social relationships, irritability and an inability to maintain a healthy emotional state and negative impact on the quality of life (16-18).

Results of our study highlight male preponderance in mandibular fractures. It was also revealed that the majority of the fractures in both males and females were in the age group of 21 to 40 years, which was consistent with previous reports. The reasons stated previously were that men in this age group take part in dangerous exercises and sports, drive carelessly, and are most likely to be involved in violence (19-22).

Our study showed that road traffic accident was the most common mechanism of injury, which was consistent with previous studies $(2,5,23)$. Road traffic accidents seem to be the most common mechanism of injury in rural areas while in urban areas assault, fights, gunshot wounds, and other acts of violence are the largest contributors to these injuries (5). Sports and Gunshot wounds were the least common causes of mechanism of injury in our study.

In our study, parasymphysis fracture was the most common followed by angle and condyle fractures, which was similar to that reported by Sirimaharaj and Pyungtanasup (9). However, Galvan reported that body fractures were more common followed by parasymphysis fractures (8). Coronoid fracture was the least common type reported in our study. This was in agreement with the studies of Galvan (8) and Khan et al. (10). Overall, the fracture patterns in our study were in close agreement with previous studies. Galvan discussed that mandible fracture site depends upon many factors like mechanism of injury, magnitude and direction of impact force, prominence of the mandible and anatomy of the site (8). Also, it depends on direction of the victim's head position along with the physical characteristics of the mandible.

Special patterns of mandibular fractures, which have not been frequently discussed in the literature, were reported in our study. Contralateral multiple fractures of the mandible occur commonly because of the unique anatomy of the mandible. In general, the unique shape tends to make double unilateral mandibular fractures rare. The incidence of multiple unilateral mandibular fractures was rarely reported. Triple unilateral pattern is a type, which was seen in one subject in our study population. Triple unilateral fractures of mandible (unilateral fractures of parasymphysis, angle and subcondylar) are difficult to treat because they involve a dentition free segment of bone adding to the challenges of fracture reduction. Such triple unilateral mandibular fracture is extremely rare and so far has not been reported in the lit- 
Table 4. Distribution of Age and Gender Against Reason for Trauma

\begin{tabular}{|c|c|c|c|c|c|c|c|c|}
\hline & \multicolumn{4}{|c|}{ Age } & \multirow[t]{2}{*}{ P-Value } & \multicolumn{2}{|c|}{ Gender } & \multirow[t]{2}{*}{ P-Value } \\
\hline & $<\mathbf{2 0}$ & $21-40$ & $41-60$ & $61-80$ & & Male & Female & \\
\hline Assault & $4(3.5)$ & $14(3.5)$ & $8(6.7)$ & $0(0)$ & \multirow{5}{*}{$<0.001$} & $24(4.2)$ & $2(2.5)$ & \multirow{5}{*}{0.458} \\
\hline Fall & $5(4.4)$ & $29(7.3)$ & $10(8.3)$ & $1(4.5)$ & & $42(7.3)$ & $3(3.8)$ & \\
\hline Gunshot injury & $0(0)$ & $0(0)$ & $0(0)$ & $2(9.1)$ & & $2(0.3)$ & $0(0)$ & \\
\hline RTA & $102(89.5)$ & $349(87.9)$ & $101(84.2)$ & $19(86.4)$ & & $497(86.6)$ & $74(93.7)$ & \\
\hline Sports & $3(2.6)$ & $5(1.3)$ & $1(0.8)$ & $0(0)$ & & $9(1.6)$ & $0(0)$ & \\
\hline
\end{tabular}

Table 5. Relationship Between Mechanism of Injury and Site of Fracture

\begin{tabular}{|c|c|c|c|c|c|}
\hline & & Assault & Fall & RTA & Sports \\
\hline Symphysis & OR, CI, P-value & $1.68,(0.658-4.29), 0.2$ & $(1.77-6.52),<0.001$ & $0.377,(0.22-0.64),<0.001$ & $1.57,(0.32-7.68), 0.57$ \\
\hline Parasym & OR, CI, P-Value & $0.717,(0.32-1.59), 0.41$ & $0.707,(0.38-1.31), 0.266$ & $1.59,(0.99-2.54), 0.05$ & $0.49,(0.12-1.98), 0.307$ \\
\hline Body & OR, CI, P-Value & $0.696,(0.21-2.36), 0.559$ & $0.114,(0.016-0.84), 0.114$ & $2.14,(0.96-4.78), 0.059$ & $0.67,(0.08-5.43), 0.708$ \\
\hline Angle & OR, CI, P-Value & $1.684,(0.74-3.86), 0.213$ & $0.285,(0.1-0.81), 0.012$ & $1.07,(0.62-1.86), 0.79$ & $2.52,(0.67-9.51), 0.157$ \\
\hline Ramus & OR, CI, P-Value & $1.75,(0.22-13.85), 0.591$ & - & $2.04,(0.26-15.69), 0.486$ & - \\
\hline Coronoid & OR, CI, P-Value & $4.65,(0.98-22.15), 0.034$ & - & $0.79,(0.17-3.62), 0.789$ & - \\
\hline Condyle & OR, CI, P-Value & $0.315,(0.07-1.35), 0.101$ & $0.914,(0.46-2.08), 0.945$ & $1.57,(0.83-2.99), 0.17$ & $0.484,(0.06-3.90), 0.49$ \\
\hline
\end{tabular}

erature. Double fractures were also reported in our study with double contralateral in 151 subjects and double unilateral in 42 subjects. Double unilateral fractures are rare and Cillo and Ellis discussed the treatment of 31 cases of double unilateral fractures (24). Bilateral fractures were seen in 74 subjects with respect to condyles, 29 subjects with parasymphysis and 12 subjects with respect to body fractures. Marker et al. discussed the various condylar fracture patterns out of which $28 \%$ were bilateral (25).

Within the limits of our study we could conclude that mandibular fractures can be complicated, demanding and have a compelling impact on patient's quality of life. Our study reported that parasymphysis was the most common region involved in mandible fractures. Mandible fractures occur in all age groups in a wide range of social settings. Their causes often reflect shifts in trauma patterns over time. The prevalence of various types of mandibular fractures from the anatomic standpoint and their correlation to etiology can be helpful for the clinician for effective early management.

\section{Acknowledgments}

We are thankful to all the staff for helping with the data retrieval.

\section{Footnote}

Funding/Support: We declare that there was no financial support from any source.

\section{References}

1. Ogundare BO, BonnickA, Bayley N. Pattern of mandibular fractures in an urban major trauma center.J Oral Maxillofac Surg. 2003;61(6):713-8. doi: 10.1053/joms.2003.50118. [PubMed: 12796884].

2. Sakr K, Farag IA, Zeitoun IM. Review of 509 mandibular fractures treated at the University Hospital, Alexandria, Egypt. Br J Oral Maxillofac Surg. 2006;44(2):107-11. doi: 10.1016/j.bjoms.2005.03.014. [PubMed: 15896887].

3. Vetter JD, Topazian RG, Goldberg MH, Smith DG. Facial fractures occurring in a medium-sized metropolitan area: recent trends. Int J Oral Maxillofac Surg. 1991;20(4):214-6. [PubMed: 1940497].

4. Oikarinen K, Ignatius E, Kauppi H, Silvennoinen U. Mandibular fractures in northern Finland in the 1980s-a 10-year study. Br J Oral Maxillofac Surg. 1993;31(1):23-7. [PubMed: 8431409].

5. King RE, Scianna JM, Petruzzelli GJ. Mandible fracture patterns: a suburban trauma center experience. Am J Otolaryngol. 2004;25(5):301-7. [PubMed: 15334392].

6. de Matos FP, Arnez MF, Sverzut CE, Trivellato AE. A retrospective study of mandibular fracture in a 40-month period. Int JOral Maxillofac Surg. 2010;39(1):10-5. doi:10.1016/j.ijom.2009.10.005. [PubMed: 19914802].

7. Elgehani RA, Orafi MI. Incidence of mandibular fractures in Eastern part of Libya. Med Oral Patol Oral Cir Bucal. 2009;14(10):529-32. [PubMed: 19680213].

8. Galvan G. Evaluation of mandibular fractures in a tertiary military hospital: A 10-year retrospective study. Philipp J Otolaryngol Head Neck Surg. 2011;26(1):16-20. 
9. Sirimaharaj W, Pyungtanasup K. The epidemiology of mandibular fractures treated at Chiang Mai University Hospital: a review of 198 cases. J Med Assoc Thai. 2008;91(6):868-74. [PubMed: 18697387].

10. Khan A, Salam A, Khitab U, Tariqkhan M. Pattern of mandibular fractures: A study. Pakistan Oral Dent J. 2009;29:221-4.

11. Fridrich KL, Pena-Velasco G, Olson RA. Changing trends with mandibular fractures: a review of 1,067 cases. J Oral Maxillofac Surg. 1992;50(6):586-9. [PubMed: 1593318].

12. Olson RA, Fonseca RJ, Zeitler DL, Osbon DB. Fractures of the mandible: a review of 580 cases. J Oral Maxillofac Surg. 1982;40(1):23-8. [PubMed: 6950035].

13. Scherer M, Sullivan WG, Smith DJ, Phillips LG, Robson MC. An analysis of 1,423 facial fractures in 788 patients at an urban trauma center. $J$ Trauma. 1989;29(3):388-90. [PubMed: 2648018].

14. Haug RH, Foss J. Maxillofacial injuries in the pediatric patient. Oral Surg Oral Med Oral Pathol Oral Radiol Endod. 2000;90(2):126-34. doi: 10.1067/moe.2000.107974. [PubMed: 10936829].

15. Glazer M, Joshua BZ, Woldenberg Y, Bodner L. Mandibular fractures in children: analysis of 61 cases and review of the literature. Int J Pediatr Otorhinolaryngol. 2011;75(1):62-4. doi: 10.1016/j.ijporl.2010.10.008. [PubMed: 21035876].

16. Barbosa TS, Gaviao MB. Oral health-related quality of life in children: part I. How well do children know themselves? A systematic review. Int J Dent Hyg. 2008;6(2):93-9. doi: 10.1111/j.1601-5037.2007.00276.x. [PubMed: 18412720].

17. Cortes MI, Marcenes W, Sheiham A. Impact of traumatic injuries to the permanent teeth on the oral health-related quality of life in 12-14year-old children. Community Dent Oral Epidemiol. 2002;30(3):193-8. [PubMed: 12000342].

18. Ramos-Jorge ML, Bosco VL, Peres MA, Nunes AC. The impact of treatment of dental trauma on the quality of life of adolescents - a casecontrol study in southern Brazil. Dent Traumatol. 2007;23(2):114-9. doi: 10.1111/j.1600-9657.2005.00409.x. [PubMed: 17367459].

19. Dongas P, Hall GM. Mandibular fracture patterns in Tasmania, Australia. Aust Dent J. 2002;47(2):131-7. [PubMed: 12139266].

20. Oji C. Jaw fractures in Enugu, Nigeria, 1985-95. Br J Oral Maxillofac Surg. 1999;37(2):106-9. doi: 10.1054/bjom.1997.0083. [PubMed: 10371311].

21. Moshy J, Mosha HJ, Lema PA. Prevalence of maxillo-mandibular fractures in mainland Tanzania. East Afr Med J. 1996;73(3):172-5. [PubMed: 8698015].

22. Karyouti SM. Maxillofacial injuries at Jordan University Hospital. Int J Oral Maxillofac Surg. 1987;16(3):262-5. [PubMed: 3112254].

23. Bataineh AB. Etiology and incidence of maxillofacial fractures in the north of Jordan. Oral Surg Oral Med Oral Pathol Oral Radiol Endod. 1998;86(1):31-5. [PubMed: 9690242].

24. Cillo JJ, Ellis E3. Treatment of patients with double unilateral fractures of the mandible. J Oral Maxillofac Surg. 2007;65(8):1461-9. doi: 10.1016/j.joms.2006.08.013. [PubMed:17656269].

25. Marker P, Nielsen A, Bastian HL. Fractures of the mandibular condyle. Part 1: patterns of distribution of types and causes of fractures in 348 patients. Br J Oral Maxillofac Surg. 2000;38(5):417-21. doi: 10.1054/bjom.2000.0317. [PubMed: 11010766]. 